DOI: https://doi.org/10.11144/Javeriana.upsy18-5.apes

\title{
Advances on Parental Educational Styles Predictors of Internalizing and Externalizing Behaviors in Children*
}

\section{Avances sobre estilos educativos parentales predictores de comportamientos internalizantes y externalizantes en niños}

Received: 02 December 2018 | Accepted: 19 July 2019

\author{
Jaime Humberto Moreno Méndez ${ }^{a}$ \\ Universidad Miguel Hernández de Elche, España \\ ORCID: http://orcid.org/0000-0003-4087-6309 \\ José Pedro Espada Sánchez \\ Universidad Miguel Hernández de Elche, España \\ ORCID: http://orcid.org/0000-0001-5248-6258 \\ INMACUlada GÓMEz Becerra \\ Universidad de Almería, España \\ ORCID: http://orcid.org/0000-0002-1625-2013
}

a Correspondence author: E-mail:
jaimehm@yahoo.com

How to cite: Moreno Méndez, J. H., Espada Sánchez, J. P., \& Gómez Becerra, I. (2019). Advances on parental educational styles predictors of internalizing and externalizing behaviors in children. Universitas Psychologica, 18(5), 1-10. https://doi.org/10.11144/Jav eriana.upsy 18-5.apes

\begin{abstract}
The purposes of this study were to perform a psychometric analysis of the Parental Educational Styles Questionnaire and to evaluate its predictive validity on externalizing and internalizing problems in Colombian children. Participants were 680 parents $(M=37.34 ; S D=$ 9.2) of children aged between 8 and 12 years enrolled in public schools in Bogota, Colombia. The parental educational styles questionnaire and the child behavior checklist -parents format- were applied to the participants. The resulting model presents the best indicators of favorable fit according to confirmatory factorial analyses. These values show an internal consistence of the instrument. The results indicate that dysfunctional reaction to disobedience, communication difficulties and conflicts predicted internalizing and externalizing problems.

Keywords

parental styles; internalizing behavior; externalizing behavior; psychometric study; confirmatory analysis.
\end{abstract}

\section{RESUMEN}

Los objetivos de este estudio fueron analizar psicométricamente el Cuestionario Estilos Educativos Parentales y evaluar su validez predictiva en factores internalizantes y externalizantes en población colombiana. Los participantes fueron 680 padres $(M=37.34$; $D S=9.2)$ de niños con edades entre 8 y 12 años vinculados a colegios públicos en Bogotá, Colombia. El Cuestionario de estilos educativos parentales y la lista de chequeo del comportamiento infantil - formato para padres- se aplicaron a los participantes. El modelo resultante presenta indicadores de ajuste favorable según el análisis factorial confirmatorio. Estos valores muestran una consistencia interna del instrumento. Los resultados indican que la reacción disfuncional a la desobediencia, las dificultades de comunicación, y los conflictos predijeron problemas internalizantes y externalizantes. 
Palabras clave

estilos parentales; comportamiento internalizante; comportamiento externalizante; análisis psicométrico; análisis confirmatorio.

Various studies have reported that children can present externalizing and internalizing behavior problems and difficulties of psychosocial adjustment as a result of dysfunctional parenting styles (Alt, 2016; Chen et al., 2015; FrancoNerín, Pérez-Nieto, \& De Dios-Pérez, 2014). Due to this, it becomes necessary to have a valid and reliable instrument for the Colombian population, that allows the assessment of parental styles in order to predict such behavioral problems in children.

In the Colombian context, there has been a change on the structure and family dynamics. Currently, up to $14 \%$ of families are made up of extended families, and up to $10 \%$ are made of single families, while it is also noticeable a decrease in nuclear families by up to $30 \%$ based on previous years. This in turn has generated changes in parental styles (Ministerio de Salud, Colciencias, \& Pontificia Universidad Javeriana, 2015).

There have been some international studies that have evaluated the psychometric properties of instruments on parenting styles (Ang, Tan, \& Fam, 2016; Chakawa \& Hoglund, 2016; Kerns, Eating, \& Zeman, 2014; Young et al., 2013). These authors also concluded that the factorial structure of a categorical type of parenting styles based on Baumrind's taxonomic perspective (1971) does not provide enough clarity about parental styles; whilst a dimensional conceptualization of parental styles based on the numerical dimensions of warmth and nurturing behavior management can more accurately capture the construct.

In Spain, Gómez, Martínez de Salazar, García Barranco, Cobos and Filippo (2012) conducted a pilot study of the Educational Parenting Styles Questionnaire (CEEP), They aimed to identify parenting styles, that can be risk or protective factors for clinical problems in children aged between 6 and 12. This instrument showed high reliability of 0.92 , general content validity kappa index of 0.92 , and construct validity in each of the five scales with factorial structures whose percentages explained between 56.5 to 65.05 of variance. Gómez et al. (2012) suggested to extend the CEEP psychometric analysis to a representative sample of normal population in order to have greater predictive validity and an overall higher level of reliability.

In Latin America, other researchers have also evaluated the psychometric properties of parental styles instruments (Ballesteros, 2001; Manrique, Ghesquière, \& Van Leeuwen, 2014; Molina, Raimundi, \& Burgallo, 2017). The instruments reviewed assess certain characteristics about parenting, however, none of them allow for sufficient determination of the capacities required by parents in order to meet the needs of their children, what highlights the need to standardize those instruments with larger samples and refine their measurements.

Several studies have focused on studying the prediction of externalizing and internalizing behaviors from parental styles, albeit with diverse results. Fuentes, Salas, Bernedo and GarcíaMartín (2014), found that the authoritarian style was related to thisbehaviors; Tan, Gelley and Dedrick (2015) found that permissive and authoritarian styles were associated, and Lakin, LeRoy, Boxer, and Mahoney (2014) concluded that a negative parental alliance predicted further internalization problems.

Evidence has been found of how the same component of parental style can be a predictor of different internalization and externalization problems in children, for instance, the use of physical punishment (Chen et al., 2015), lack of communication (Cerezo, Ruiz-Esteban, Sánchez-Lacasa, \& Arense-Gonzalo, 2018; Fite, Rubens, Preddy, Raine, \& Pardini, 2014), inconsistency and ambiguity in the rules and limits (Jabagchourian, Sorkhabi, Quach, \& Strage, 2014). Contrarily, some of these might be protective factors for those problems, such as cohesion, promotion of positive behaviors, emotional competencies, establishment of firm limits, communication and affection (Cenk \& Demir, 2016; Gómez et al., 2012; Lakin et al., 2014; Newland, 2015). 
Therefore, the theoretical position on paternity that underpins the present study is proposed by Duncan, Coastworth and Greenberg (2009). From a dimensional perspective, the aforementioned authors emphasize the conscious attention on the part of parents towards their children. From this model, it is argued that the quality of relationships between parents and their children can be strengthened when parents become aware of the upbringing of their children.

In light of the above, the objectives were as follows: Firstly, to perform a psychometric analysis of the Educational Parenting Styles Questionnaire for a Colombian population. Secondly, to evaluate the predictive validity of the questionnaire on parental educational styles on internalizing and externalizing psychological problems in Colombian children.

\section{Method}

\section{Participants}

The sample included 680 parents with a mean age of 37.34 years $(S D=9.02)$ of children between 8 and 12 years old. $70.1 \%$ of the parents were mothers, whereas only $29.9 \%$ were fathers. $35.3 \%$ were in common law marriage, $27.7 \%$ were single, $21.6 \%$ were married, $5.9 \%$ were separated and, to a lesser extent, $0.9 \%$ were widowers. With regard to occupation, $54.6 \%$ of the parents were employed, $16.8 \%$ of the father and $23.1 \%$ of the mothers were employed while $14.1 \%$ of the mothers were housewives, none of the fathers were stay-at-home dads, and $10 \%$ were independent. The participants belonged to a low social economic status, and were selected for convenience.

\section{Instruments}

Parental Educational Styles Questionnaire (CEEP - Reduced version; Gómez et al., 2012). This instrument has five scales with corresponding factors as follows: Parental Practices (Promotion of positive behaviors, dysfunctional reactions to disobedience, inconsistency, proper use of corrections); Educational Styles (Democratic, permissive, ambiguous, authoritarian); Emotional Competences (Impulsiveness, emotional expression, recognitions of emotions, emotional management); Parental Role (Parental satisfaction, collaboration with school, parental overload) and Family Dynamics (family cohesion, communication, shared leisure, conflicts). The questionnaire has of 66 Likert items with four answer options (1 most of the times, 2 frequently, 3 sometimes, 4 rarely). According with Cronbach's Alpha, the total of the questionnaire showed a high reliability of 0.92 while the subscales between medium and high between 0.64 and 0.84; high content validity with an overall Kappa index of 0.92 . Regarding construct validity for all factors and scales, assumptions of sphericity, adequacy ratio of the Spanish sample and the value of the determinant have been optimally met.

Child Behavior Checklist (CBCL), parent format. Achenbach and Edelbrock's (2001) The CBCL allows to evaluate internalizing and externalizing psychological problems in children aged 4 to 16 . This checklist has a rating as follows: (0) if it is not true, (1) if sometimes it is true and (2) if it is true very often. The direct scores are transformed into $t$ scores according to the following ranges: Clinical: between 64 and 100; Borderline: between 60 and 63; Normal: between 59 and 33. Regarding content validity, 116 of the 118 items of behavioral problems are significantly associated with clinical status $-p<0.01$. It has been adapted for the Colombian population where it obtained a reliability coefficient Cronbach's Alpha of 0.83 and an internal consistency of 0.94 (Rescorla et al., 2012).

\section{Procedure}

The study was approved by the Ethics Committee of the University to which the authors belong. School principals were asked to authorize access to the participants. The research objectives 
were then explained to parents in order to obtain an informed consent to participate in the study. Subsequently, the instruments were administered to the parents collectively in the school by 6 psychologists who were previously trained by the researchers on the test and its administration. The resulting data was analyzed, and the institution was given the results of the research. Parents were given psycho-educational primers to strengthen parenting styles with their children for participation in the study.

\section{Statistical Analyses}

Based on the contribution of each original variable in each of the factors, a new model fitted to the Colombian population was obtained, and was subjected to confirmatory factor analysis (CFA) using the software AMOS 23. Other indexes were used, such as CMIN / df, which refers to the $\mathrm{c} 2$ ratio, over the degrees of freedom, GFI (goodness of global adjustment index), the CFI (comparative fit index) and RMSEA (square error approach to medium roots), AIC (Akaike information criterion). To determine the fit of the data to the model, the value of $\mathrm{c} 2$ should be meaningful, the CMIN / df, requires less than 3.0, the CFI and GFI vary between 0 and 1 , where 0 means no adjustment and one means optimal fit, values higher than 0.90 represent an acceptable fit; while values of 0.95 or higher are considered excellent. The RMSEA needs to be less than 0.08 , and preferably less than 0.06 , because if the model is greater than 0.10 , it must be rejected (Pilatti, Godoy, \& Brussino, 2012).

Correlations between scales of de CEEP and CBCL were analyzed using the Pearson coefficient. Finally, a multiple regression analysis was conducted in order to establish the predictive validity of the CEEP. The parental styles in each of the dimensions were used as predictors, and the scales of the CBCL of the internalizing and externalizing behaviors were used as criterion variables.

\section{Results}

The results of the confirmatory factor analysis (CFA) presented in Table 1 show that the indexes in the fit model are better than the rates in the original model and the one-dimensional. The resulting model presents the best indicators of favorable fit according to recommendations suggested by CFA. These values can show an internal consistence that also favors results for the scales of the instrument.

The fit model founded for the Colombian population was one-dimensional for family dynamics $(c 2=2.78 ; d f=3 ; c 2 / d f=0.93 ; \mathrm{GFI}=$ 0.99; $\mathrm{CFI}=1.00 ; \mathrm{TLI}=1.00$; $\mathrm{RMSEA}=0.00$; AIC $=26.78)$, two factors for parental role $(c 2$ $=3.95 ; d f=4 ; c 2 / d f=0.99 ; \mathrm{GFI}=0.99 ; \mathrm{CFI}$ $=1.00 ; \mathrm{TLI}=1.00 ; \mathrm{RMSEA}=0.00 ; \mathrm{AIC}=$ 26.78), and parental practices ( $c 2=29.59 ; d f=$ $12 ; c 2 / d f=2.47$; GFI $=0.99 ; \mathrm{CFI}=0.97$; TLI $=0.94$; RMSEA $=0.04 ;$ AIC $=61.59)$; three factors for emotional competences $(c 2=35.33$; $d f=19 ; c 2 / d f=1.86 ;$ GFI $=0.98 ; \mathrm{CFI}=0.94$; $\mathrm{TLI}=0.91 ; \mathrm{RMSEA}=0.04 ; \mathrm{AIC}=69.33)$, and educational styles $(c 2=53.63 ; d f=31 ; c 2 / d f$ $=1.73$; $\mathrm{GFI}=0.98$; $\mathrm{CFI}=0.95$; $\mathrm{TLI}=0.94$; RMSEA $=0.03$; $\mathrm{AIC}=101.63$ ).

According to Cronbach alpha coefficient, the reliability coefficients found were the following: family dynamics $(\mathrm{a}=0.65)$, parental role $(\mathrm{a}$ $=0.53)$, emotional competences $(\mathrm{a}=0.66)$, educational styles $(\mathrm{a}=0.63)$, parental practices $(\mathrm{a}=0.60)$ and total parental educational styles $(\mathrm{a}=0.78)$. 


\section{Table 1}

Confirmatory factor analysis of the Spanish original scales and adapted scales with a Colombian sample

\begin{tabular}{|c|c|c|c|c|c|c|c|c|c|}
\hline $\begin{array}{c}\text { Total CEEP } \\
\alpha=0.78 \\
(35 \text { items })\end{array}$ & Model & $x^{2}$ & df & $\begin{array}{l}\chi^{2 /} \\
\mathrm{df}\end{array}$ & GFI & CFI & TLI & RMSEA & AIC \\
\hline \multirow{3}{*}{$\begin{array}{l}\text { Family } \\
\text { Dynamics } \\
\alpha=0.65\end{array}$} & $\begin{array}{l}\text { Original } 4 \text { related } \\
\text { factors } 13 \text { items }\end{array}$ & $68.16^{* * *}$ & 59 & 4.54 & 0.94 & 0.71 & 0.62 & 0.07 & 332.16 \\
\hline & $\begin{array}{l}\text { One-dimensional } 13 \\
\text { items }\end{array}$ & $326.45^{* *}$ & 65 & 5.02 & 0.90 & 0.75 & 0.70 & 0.09 & 378.45 \\
\hline & $\begin{array}{l}\text { Resulting One- } \\
\text { dimensional } 5 \text { items }\end{array}$ & 2.78 & 3 & 0.93 & 0.99 & 1.00 & 1.00 & 0 & 26.78 \\
\hline \multirow{3}{*}{$\begin{array}{l}\text { Parental } \\
\text { Role } \\
\alpha=0.53\end{array}$} & $\begin{array}{l}\text { Original } 3 \text { related } \\
\text { factors } 10 \text { items }\end{array}$ & $160.75^{* * *}$ & 32 & 5.02 & 0.95 & 0.67 & 0.58 & 0.07 & 206.75 \\
\hline & $\begin{array}{l}\text { One-dimensional } 10 \\
\text { items }\end{array}$ & $142.41^{* *}$ & 35 & 4.07 & 0.95 & 0.58 & 0.45 & 0.08 & 182.41 \\
\hline & $\begin{array}{l}\text { Resulting } 2 \text { related } \\
\text { factors } 5 \text { items }\end{array}$ & 3.95 & 4 & 0.99 & 0.99 & 1.00 & 1.00 & 0 & 25.95 \\
\hline \multirow{3}{*}{$\begin{array}{l}\text { Emotional } \\
\text { Competences } \\
\alpha=0.66\end{array}$} & $\begin{array}{l}\text { Original } 12 \text { items } 4 \\
\text { related factors }\end{array}$ & 283.94** & 48 & 5.91 & 0.92 & 0.59 & 0.43 & 0.09 & 343.94 \\
\hline & $\begin{array}{l}\text { One-dimensional } 12 \\
\text { items }\end{array}$ & $364.93^{* *}$ & 54 & 6.76 & 0.88 & 0.46 & 0.34 & 0.11 & 412.93 \\
\hline & $\begin{array}{l}\text { Resulting } 3 \\
\text { uncorrelated factors } \\
8 \text { items }\end{array}$ & $35.33^{*}$ & 19 & 1.86 & 0.98 & 0.94 & 0.91 & 0.04 & 69.33 \\
\hline \multirow{3}{*}{$\begin{array}{l}\text { Educational } \\
\text { Styles } \\
\alpha=0.63\end{array}$} & $\begin{array}{l}\text { Original } 4 \text { related } \\
\text { factors } 14 \text { items }\end{array}$ & $196.57^{* * *}$ & 71 & 2.77 & 96 & 0.83 & 78 & 05 & 64.57 \\
\hline & $\begin{array}{l}\text { One-dimensional } 13 \\
\text { items }\end{array}$ & $318.91^{* *}$ & 65 & 4.91 & 0.89 & 0.43 & 0.32 & 0.09 & 370.91 \\
\hline & $\begin{array}{l}\text { Resulting } 3 \text { related } \\
\text { factors } 10 \text { items }\end{array}$ & $53.63 * * *$ & 31 & 1.73 & 0.98 & 0.95 & 0.94 & 0.03 & 101.63 \\
\hline \multirow{3}{*}{$\begin{array}{l}\text { Parental } \\
\text { Practices } \\
\alpha=0.60\end{array}$} & $\begin{array}{l}\text { Original } 4 \text { related } \\
\text { factors } 16 \text { items }\end{array}$ & $465.10^{* *}$ & 98 & 4.75 & 0.91 & 0.63 & 0.55 & 0.07 & 541.10 \\
\hline & $\begin{array}{l}\text { One-dimensional } 16 \\
\text { items }\end{array}$ & $793.94^{* *}$ & 104 & 7.63 & 0.79 & 0.56 & 0.49 & 0.11 & 857.94 \\
\hline & $\begin{array}{l}\text { Resulting } 2 \text { related } \\
\text { factors } 7 \text { items }\end{array}$ & $29.59^{* * *}$ & 12 & 2.47 & 0.99 & 0.97 & 0.94 & 0.04 & 61.59 \\
\hline
\end{tabular}

GFI=Global goodness Fit Index;

$\mathrm{CFI}=$ Comparative Fit Index;

RMSEA $=$ Root mean squared error

TLI = Trucker-Lewis Index;

$\mathrm{AIC}=$ Akaike information criterion

Table 2 presents the results corresponding to the multiple regression analysis. As derived from the results obtained, dysfunctional reaction to disobedience, family cohesion, inconsistency, communication and conflicts predict internalizing behavior problems. It is important to note that a dysfunctional reaction to disobedience in parents significantly predicts anxious-depressive, isolated-depressive behavior, somatic complaints, and total internalizing behaviors in children. Conflicts is another variable that allows to predict isolateddepressive, somatic complaints and total internalizing behaviors.
Table 2

Multiple regression analysis of parental style on the scores of internalizing behavior problems

\begin{tabular}{lccc}
\hline \multicolumn{1}{c}{ Predictors } & $\beta$ & $\mathrm{R}^{2}$ adjust. & $\Delta \mathrm{F}$ \\
\hline Anxious-depressive & & & \\
$\quad$ Dysfunctional reaction to disobedience & 0.281 & 0.134 & $106.023^{* * *}$ \\
Impulsiveness & 0.108 & 0.145 & $10.022^{* * *}$ \\
$\quad$ Parental overload & 0.217 & 0.151 & $5.788^{*}$ \\
$\quad$ Help with school & -0.150 & 0.167 & $13.736^{* * *}$ \\
$\quad$ Promoting positive behaviors & -0.085 & 0.172 & $4.992^{*}$ \\
\hline Isolated depressive & & & \\
$\quad$ Dysfunctional reaction to disobedience & $0.120^{*}$ & & \\
$\quad$ Family Dynamics & $-0.114^{*}$ & & \\
$\quad$ Impulsiveness & $0.134^{*}$ & 0.204 & $0.009^{* *}$ \\
$\quad$ Conflicts & $0.119^{*}$ & & \\
\hline Somatic complaints & & & \\
$\quad$ Dysfunctional reaction to disobedience & $0.236^{* *}$ & & \\
$\quad$ Conflicts & $0.156^{* *}$ & 0.124 & $0.014^{* *}$ \\
$\quad$ Promote positive behavior & $-0.121^{* *}$ & & \\
\hline Total Internalizing Behavior Problems & & & \\
$\quad$ Dysfunctional reaction to disobedience & $0.203^{* *}$ & & \\
$\quad$ Family cohesion & $-0.108^{*}$ & & \\
Inconsistency & $0.179^{* *}$ & 0.242 & $0.012^{* *}$ \\
$\quad$ Communication & $-0.123^{* *}$ & & \\
$\quad$ Conflicts & $0.138^{* *}$ & & \\
\hline
\end{tabular}

Note: $\beta$ (standarized coefficients),

$\mathrm{R}^{2}$ adjust. (adjusted coefficient of determination), $\Delta \mathrm{F}$ (change in the statistical test). ${ }^{*} \mathrm{p}<=0.05 ; * * \mathrm{p}<0.01$.

In Table 3, the results on the multiple regression analysis show that the dysfunctional reaction to disobedience, communication, conflicts, overload and parental satisfaction predicts externalizing problems. Specifically, the dysfunctional reaction to disobedience and conflicts in parents predict both rule-breaking behavior and aggressive behavior in children.

\section{Table 3}

Multiple regression analysis of parental styles on the scores of externalizing behaviors

\begin{tabular}{lccc}
\hline \multicolumn{1}{c}{ Predictors } & $\beta$ & $\mathrm{R}^{2}$ adjust. & $\Delta \mathrm{F}$ \\
\hline Rule-breaking behavior & & & \\
Dysfunctional reaction to disobedience & $0.237^{* *}$ & & \\
Parental satisfaction & $-0.136^{* *}$ & & \\
Parental overload & $0.159^{* *}$ & 0.226 & $0.012^{*}$ \\
Conflicts & $.0157^{* *}$ & & \\
Promote positive behavior & $-0.127^{*}$ & & \\
\hline Aggressive Behavior & & & \\
Dysfunctional reaction to disobedience & $0.349^{* *}$ & & \multirow{2}{*}{$0.020^{* *}$} \\
Communication & $-0.157^{* *}$ & 0.261 & \\
Conflicts & $0.173^{* *}$ & & \\
\hline Total Externalizing Problems & & & \\
Dysfunctional reaction to disobedience & $0.310^{* *}$ & & \\
Communication & $-0.120^{* *}$ & & \\
Conflicts & $0.172^{* *}$ & 0.280 & $0.010^{* *}$ \\
Parental overload & $0.103^{*}$ & & \\
Parental Satisfaction & $-0.110^{*}$ & & \\
\hline
\end{tabular}

Note: $\beta$ (standarized coefficients), $\mathrm{R}^{2}$ adjust. (adjusted coefficient of determination),

$\mathrm{R} \Delta$ (change in the coefficient of determination). $* \mathrm{p}<0.05 ; * * \mathrm{p}<0.01$. 


\section{Discussion}

One purpose of this study was to establish the psychometric properties of the Parental Educational Styles questionnaire (CEEP) for a Colombian population. From the confirmatory analysis, it was found that the CEEP model for Colombia had values indicating an optimal fit for all subscales and the total scale. The total scale is superior to the Spanish model, which showed acceptable levels; just as the one evaluated by Manrique et al. (2014) in Peru. The latter had a moderate adjustment, and as well as the instrument analyzed by Penelo, Viladrich and Domènech (2010) which was acceptable. Similar to the research by Sheffield, Waller, Emanuelli, Murray, \& Meyer (2006), the AFC, showed a shorter version of the original instrument.

The fit model founded for the Colombian population was one-dimensional for family dynamics, two factors for parental role, and parental practices; three factors for emotional competences, and educational styles. The findings of the present study provide a numerical dimensional perspective of parental styles that permit to capture this construct more accurately that structure of a categorical type of parenting styles (Ang et al., 2016; Chakawa \& Hoglund, 2016; Kerns et al., 2014; Young et al., 2013).

The results also show that the instrument allows evaluating with more determination parents skills about parenting in order to meet the needs of their children, as previous studies have indicated (Ballesteros, 2001; Manrique et al., 2014; Molina et al., 2017).

Another purpose was to evaluate its predictive validity on externalizing and internalizing problems in Colombian children. The factors that constituted risk predictors of internalizing behaviors were dysfunctional reaction to disobedience, inconsistency, conflicts, and difficulties in family cohesion and communication. In turn, the results indicate that a dysfunctional reaction to disobedience, conflicts, parental overload, problems in communication and lack of parental satisfaction predicted externalizing behavior problems. One dysfunctional reaction to disobedience, is the use of punishment by parents which has an impact in the manifestation of externalizing behaviors in children. This can be explained by the association between coercion and imposition, when they are not accompanied by dialogue and affection have an effect more harmful than adaptive (Uji, Sakamoto, Adachi, \& Kitamura, 2014).

When conflicts arise within the family characterized by the existence of discussions and lack of communication among their members, they predict internalizing behavior patterns, as well as externalizing behavior in children (Estévez, Jiménez, \& Moreno, 2018; Livas \& Polo, 2014; Fernández-Daza \& FernándezParra, 2012; Percy, Creswell, Garner, O’Brien, \& Murray, 2016).

For their part, Pereira, Negrao, Soares and Mesman (2013) point out that paternal stress and family conflict are predictors of severe discipline in mothers. Additionally, Malczyk and Lawson (2017) conclude that parents who are overwhelmed with paternity tend to control their children less. Both influences have a significant negative impact on the stability and emotional behavior of children. Chappel, Suldo and Ogg (2014) argue that family conflict is inversely related to children's emotional satisfaction and safety.

Communication has been the protective factor encountered for both externalizing and internalizing behaviors. This can be explained by families that have firm parenting styles, sustained by criteria that instill autonomy for all members and promote adequate, affection-based relationships within the family. These families present the best results in the education of children (Cerezo, et al., 2018; Duncan et al., 2009; Jabagchourian et al., 2014) and it generates between parents and children a high positive effect on the relationship (Gómez et al., 2012; Newland, 2015).

In conclusion, it can be said that this study contributes to having a reliable and valid instrument for the dimensional evaluation of parenting styles with a Colombian sample. This is underpinned by the fact that most of the studies have been conducted with North American, Asian and European populations (Alt, 2016; 
Budd, Danko, Li, \& Henriquez, 2015; Cenk \& Demir, 2016; Kerns et al., 2014; Young, et al., 2013).

This research has important clinical implications at the level of the evaluation of parental educational styles in Colombian population and their impact on the internalizing and externalizing behavior problems in the period of middle childhood. Research also solves one limitation of the study carried out by Gómez et al. (2012), wherein data was provisional for the negligible sample; in addition, the CBCL scales were ultimately deemed invalid.

At the same time, this paper provides information of interest for the prevention of psychological problems in children and for parent counseling on childrearing. This is due to the fact that different family dynamics and parental roles were identified, as were styles and practices that constitute risk factors / protective factors for the behavioral and emotional problems of children.

\section{Limitations and Future Directions}

It was found that this instrument has not been used with clinical samples, and the findings can only be generalized for a sample with characteristics similar to the one evaluated in the present study. In this regard, it is important to extend this study with samples from different socioeconomic status and cultures and with different clinical characteristics because parental styles could have a different predictive role in European, Asian or North American countries where the rules and regulations are set differently from Colombia. Likewise, it is suggested to include another instrument to account for the association of parental styles with the adaptive behavior of children on a personal, family, school and social level, given the implications of the styles of aging on children's different areas of adjustment.

\section{Acknowledgments}

The authors sincerely thank the participating parents for their cooperation with this project.

\section{References}

Achenbach, T. M., \& Rescorla, L. A. (2001). Manual for the ASEBA age forms and profiles. Burlington, VT: University of Vermont.

Alt, D. (2016). Using structural equation modeling and multidimensional scaling to assess female college students' academic adjustment as a function of perceived parenting styles. Current Psychology, 35(4), 549-561. https://doi.org/10.1007/s12144-0 15-9320-3

Ang, C., Tan, J., \& Fam, S. (2016). Psychometric properties of the training parenting style scale in a Malaysian sample of adolescents: Factor analysis, internal consistency, and measurement invariance. Journal of Child and Family Studies, 25(5), 1505-1514. https ://doi.org/10.1007/s10826-015-0333-1

Ballesteros, B. P. (2001). Conductas parentales prevalentes en familias de estratos 1 y 2 de Bogotá. [Prevalent parental behaviors in families of socioeconomic status 1 and 2 in Bogotá]. Suma Psicológica, 8(1), 95-142. http://publicaciones.konradlorenz. edu.co/index.php/sumapsi/article/view/230

Baumrind, D. (1971). Current patterns of parental authority. Developmental Psychology, 4(1, Pt2). https://doi.org/10.103 7/h0030372

Budd, K. S., Danko, C. M., Li, Y., \& Henriquez, S. (2015). Assessing childrearing attitudes: validation of a shortened version of the parenting questionnaire. Parenting: Science and Practice, 15(1), 39-54. https:/ /doi.org/10.1080/15295192.2015.992737

Cenk, D. S., \& Demir, A. (2016). The relationship between parenting style, gender and academic achievement with optimism among Turkish adolescents. Current Psychology, 35(4), 720-728. https:// doi.org/10.1007/s12144-015-9375-1

Cerezo, F., Ruiz-Esteban, C., Sánchez-Lacasa, C., \& Arense-Gonzalo, J. J. (2018). Dimensions of parenting styles, social climate, and bullying victims in primary and secondary education. Psicothema, 30(1), 
Jaime Humberto Moreno Méndez, José Pedro Espada Sánchez, Inmaculada Gómez Becerra.

59-65. https://doi.org/10.7334/psicothema 2016.360

Chakawa, A., \& Hoglund, W. L. G. (2016). Measuring parent cultural socialization practices: Extending the research to diverse racial-ethnic groups in Canada. Canadian Journal of Behavioural Science / Revue canadienne des sciences $d u$ comportement, 48(2), 121-131. https://doi.org/10.1037/cbs 0000028

Chappel, A. M., Suldo, S. M., \& Ogg, J. A. (2014). Associations between adolescents' family stressors and life satisfaction. Journal of Child and Family Studies, 23(1), 76-84. h ttps://doi.org/10.1007/s10826-012-9687-9

Chen, F. R., Raineb, A., Rudo-Huttc, A. S., Glennd, A L., Soyfere, L., \& Granger, D. A. (2015). Harsh discipline and behavior problems: The moderating effects of cortisol and alpha-amylase. Biological Psychology, 104, 19-27. https://doi.org/10.1 016/j.biopsycho.2014.11.005

Duncan, L. G., Coatsworth, J. D., \& Greenberg, M. T. (2009). A model of mindful parenting: Implications for parent-child relationships and prevention research. Clinical Child and Family Psychology Review, 12(3), 255-270. https://doi.org/10.1007/s10 567-009-0046-3

Estévez, E., Jiménez, T. I., \& Moreno, D. (2018). Aggressive behavior in adolescence as a predictor of personal, family, and school adjustment problems. Psicothema 30(1), 66-73. https://doi.org/10.7334/psicothema 2016.294

Fernández-Daza, M. P., \& Fernández-Parra, A. (2013). Problemas de comportamiento y competencias psicosociales en niños y adolescentes institucionalizados. [Behavior problems and psychosocial skills in institutionalized children and adolescents]. Universitas Psychologica, 12(3), 797-810. https://doi.org/10.11144/Ja veriana.UPSY12-3.pccp

Fite, P. J., Rubens, S. L., Preddy, T. M., Raine, A., \& Pardini, D. A. (2014). Reactive/ proactive aggression and the development of internalizing problems in males: the moderating effect of parent and peer relationships. Aggressive Behavior, 40(1), 69-78. https://doi.org/10.1002/ab.21498

Franco-Nerín, N., Pérez-Nieto, M. A., \& de Dios-Pérez, M. J. (2014). Relación entre los estilos de crianza parental y el desarrollo de ansiedad y conductas disruptivas en niños de 3 a 6 años. [Relationship between parenting styles and the development of anxiety and disruptive behaviors in children from 3 to 6 years old]. Revista de Psicología Clínica con Niños y Adolescentes, 1(2),149-156. http://www.revistapcna.com /sites/default/files/6-rpcna vol.2.pdf

Fuentes, M. J., Salas, M. D., Bernedo, I. M., \& García-Martín, M. A. (2014). Impact of the parenting style of foster parents on the behaviour problems of foster children. Child: Care, Health and Development, 41 (5), 704-711. https://doi.org/10.1111/cch.1221 5

Gómez, I. G., Martínez de Salazar, A. A., García Barranco, R., Cobos, L. S., \& Filippo, C. (2012). Validación del cuestionario de estilos educativos parentales: estudio piloto. [Validation of the questionnaire of parental educational styles: pilot study]. Comunicación invitada en el II Symposium Nacional de Psicología Clínica y de la Salud con Niños y Adolescentes. Elche, Alicante. Jabagchourian, J., Sorkhabi, N., Quach, W., \& Strage, A. (2014). Parenting styles and practices of latino parents and latino fifth graders' academic, cognitive, social, and behavioral outcomes. Hispanic Journal of Behavioral Sciences, 36(2), 175-192. https:// doi.org/10.1177/0739986314523289

Kerns, C. E., Comer, J. S., \& Zeman, J. (2014). A preliminary psychometric evaluation of a parent-report measure of child emotional awareness and expression in a sample of anxious youth. Cognitive Therapy and Research, 38(3), 349-357. https://doi.org/1 0.1007/s10608-014-9596-x

Lakin, R., LeRoy, M., Boxer, P., \& Mahoney, A. (2014). Interaction between the parenting alliance and parent-child activities in a clinic-referred sample of 2 to 18 -year-olds. 
Journal of Child and Family Studies, 23(2), 303-311. https://doi.org/10.1007/s10826-0 $12-9697-7$

Livas, G., \& Polo, A. J. (2014). ParentChild cultural value gaps and depressive symptoms among Mexican American youth. Journal of Child and Family Studies, 23(2), 189-199. https://doi.org/10.1007/s1 0826-013-9724-3

Malczyk, B. R., \& Lawson, H. A. (2017). Parental monitoring, the parent-child relationship and children's academic engagement in mother-headed single-parent families. Children and Youth Services Review, 73, 274282. Retrieved from https://doi.org/10.101 6/j.childyouth.2016.12.019

Manrique, D. L., Ghesquière, P., \& Van Leeuwen, K. J. (2014). Evaluation of a parental behavior scale in a Peruvian context. Journal of Child and Family Studies, 23(5), 885-894. https://doi.org/10.1007/s10826-0 13-9744-z

Ministerio de Salud, Colciencias, \& Pontificia Universidad Javeriana (2015). Encuesta Nacional de Salud Mental. [National Mental Health Survey] Colombia. http://www.odc. gov.co/Portals/1/publicaciones/pdf/consum o/estudios/nacionales/CO031102015-salud mental_tomol.pdf

Molina, M. F., Raimundi, M. J., \& Bugallo, L. (2017). La percepción de los estilos de crianza y su relación con las autopercepciones de los niños de Buenos Aires: Diferencias en función del género. [Perceived Parenting Styles and their Relation to Self-perceptions of Children from Buenos Aires: Differences by Gender] Universitas Psychologica, 16(1), 1-12. https:/ /doi.org/10.11144/Javeriana.upsy16-1.pecr

Newland, L. (2015). Family well-being, parenting, and child well-being: Pathways to healthy adjustment. Clinical Psychologist, 19(1), 3-14. https://doi.org/10.1111/cp.120 59

Penelo, E., Viladrich, C., \& Domènech, J. M. (2010). Perceived parental rearing style in childhood: internal structure and concurrent validity on the Egna Minnen
Beträffande Uppfostran-Child Version in clinical settings. Comprehensive Psychiatry, 51 (4), 434-442. https://doi.org/10.1016/j.c omppsych.2009.08.003

Percy, R., Creswell, C., Garner, M., O'Brien, D. \& Murray, L. (2016). Parents' verbal communication and childhood anxiety: A systematic review. Clinical Child and Family Psychology Review, 19(1), 55-75. https://doi .org/10.1007/s10567-015-0198-2

Pereira, M., Negrao, M., Soares, I., \& Mesman, J. (2013). Predicting harsh discipline in at-risk mothers: the moderating effect of socioeconomic deprivation severity. Journal of Child and Family Studies, 24(3), 725-733. https://doi.org/10.1007/s10826-0 13-9883-2

Pilatti, A., Godoy, J. C., \& Brussino, S. A. (2012). Análisis de factores que influyen sobre el uso de alcohol de niños: Un path análisis prospectivo. [Analysis of factors that influence alcohol use in children: A Prospective path analysis] Health and Addictions, 12(2), 155-192. http://www.red alyc.org/pdf/264/26429848005.pdf

Rescorla, L., Ivanova, M. Y., Achenbach, T. M., Begovac, I., Chahed, M., Drugli, M. B., ... Zhang, E. (2012). International epidemiology of child and adolescent psychopathology II: Integration and applications of dimensional findings from 44 societies. Journal of the American Academy of Child Eु Adolescent Psychiatry, 51 (12), 1273-1283. https://doi.org/10.1016 j.jaac.2012.09.012.

Sheffield, A., Waller, G., Emanuelli, F., Murray, J., \& Meyer, C. (2006). Links between parenting and core beliefs: Preliminary psychometric validation of the young parenting inventory. Cognitive Therapy and Research, 29(6), 787-802. https://doi.org/1 0.1007/s10608-005-4291-6

Tan, T. X., Gelley, C. D., \& Dedrick, R. F. (2015). Non-child-related family stress, parenting styles, and behavior problems in school-age girls adopted from China. Journal of Child and Family Studies, 24(10), 2881-2891. htt ps://doi.org/10.1007/s10826-014-0092-4 
Uji, M., Sakamoto, A., Adachi, K., \& Kitamura, T. (2014). The impact of authoritative, authoritarian, and permissive parenting styles on children's later mental health in Japan: Focusing on parent and child gender. Journal of Child and Family Studies, 23(2), 293-302. https://doi.org/10.1007/s10826-0 13-9740-3

Young, B. J., Wallace, D. P., Imig, M., Borgerding, L., Brown-Jacobsen, A. M., \& Whiteside, S. P. H. (2013). Parenting behaviors and childhood anxiety: A psychometric investigation of the EMBU-C. Journal of Child and Family Studies, 22 (8), 1138-1146. https://doi.org/10.1007/s10826-012-9677-y

\section{Notes}

* Research article. 